\title{
Recent topics on the regulatory mechanism of ecdysteroidogenesis by the prothoracic glands in insects
}

\section{Yoshiaki Tanaka*}

Insect Growth Regulation Research Unit, Division of Insect Science, National Institute of Agrobiological Sciences, Tsukuba, Japan

\section{Edited by:}

Shogo Matsumoto, Advanced

Science Institute - RIKEN, Japan

\section{Reviewed by:}

Ryusuke Niwa, University of Tsukuba, Japan

Shinji Nagata, University of Tokyo, Japan

\section{*Correspondence:}

Yoshiaki Tanaka, Insect Growth

Regulation Research Unit, Division of Insect Science, National Institute of Agrobiological Sciences, 1-2 Owashi, Tsukuba, Ibaraki, 3058634 Japan. e-mail:yoshiaki@affrc.go.jp
Molting and metamorphosis are strictly regulated by steroid hormones known as ecdysteroids. It is now widely recognized that ecdysteroid biosynthesis (ecdysteroidogenesis) in the prothoracic gland (PG) is regulated by the tropic factor prothoracicotropic hormone (PTTH). However, the importance of PTTH in the induction of molting and metamorphosis remains unclear, and other mechanisms are thought to be involved in the regulation of ecdysteroidogenesis by the PG. Recently, new regulatory mechanisms, prothoracicostatic factors, and neural regulation have been explored using the silkworm, Bombyx mori, and two circulating prothoracicostatic factors, prothoracicostatic peptide (PTSP) and Bommomyosuppressin (BMS), have been identified. Whereas PTTH and BMS are secreted from the brain, PTSP is secreted from the peripheral neurosecretory system - the epiproctodeal gland - during the molting stage. The molecular basis of neural regulation of ecdysteroidogenesis has been revealed for the first time in $B$. mori. The innervating neurons supply both Bommo-FMRF related peptide (BRFa) and orcokinin to maintain low levels of ecdysteroids during the feeding stage. These complex regulatory mechanisms - involving tropic and static factors, peripheral neurosecretory cells as well as the central neuroendocrine system, and neural regulation in addition to circulating factors collaborate to regulate ecdysteroidogenesis. Thus, together they create the finely tuned fluctuations in ecdysteroid titers needed in the hemolymph during insect development.

Keywords: neuropeptide, prothoracicostatic factor, innervating neuron, prothoracic gland, Bombyx mori, ecdysteroidgenesis, peripheral neurosecretory cell

\section{INTRODUCTION}

Insects are an ideal model system for studying how the regulatory mechanisms of developmental timing are coordinated with growth. The developmental transitions of insects (i.e., molting and metamorphosis) are strictly regulated by steroid hormones known as ecdysteroids. The biosynthesis of ecdysteroids, referred to as ecdysteroidogenesis, occurs predominantly in the prothoracic glands (PGs) during larval development (Gilbert et al., 2002). Since Kopeć (1922) suggested that the larval brain of the gypsy moth Lymantria dispar secretes a factor necessary for molting, attempts have been made to purify and clone this insect "brain hormone" (subsequently called prothoracicotropic hormone, PTTH). It is now widely recognized that ecdysteroid biosynthesis in the PGs is stimulated by PTTH (Kawakami et al., 1990; Mizoguchi et al., 1990); however, the importance of PTTH in the induction of molting and metamorphosis remains unclear. Removal of the brain in larvae does not result in developmental arrest, and such animals can often initiate metamorphic development, although their developments considerably delay both in the hawkmoth Manduca sexta (Truman, 1972) and in the silkworm Bombyx mori except for one hybrid race, J122 × C115 (Kobayashi, 1957). The loss of PTTH signal in the fruit fly, Drosophila melanogaster, does not cause mortality but leads to a delay in metamorphosis due to a low ecdysteroid titer, and the extended feeding period gives rise to bigger pupae and adults (McBrayer et al., 2007; Rewitz et al., 2009b). These data suggest that PTTH is required for the precise regulation of ecdysteroidogenesis but is not a crucial gatekeeper to initiate and maintain steroid biosynthesis in the PGs. In other words, other regulatory mechanisms may be involved in the regulation of ecdysteroidogenesis by the PGs.

In this review, recent studies on the regulatory mechanism of ecdysteroidogenesis by the PGs are described. In particular, I focus on humoral factors and on the neural control of ecdysteroidogensis that have been mostly explored in B. mori.

\section{HUMORAL FACTORS}

The importance of the negative regulation of ecdysteroidogenesis has been recognized, and factors that inhibit ecdysteroidogenesis in several insect species have been described and characterized (Table 1). For example, hormonal inhibition of the PGs by the brain has been reported in locusts (Carlisle and Ellis, 1968). Crude extracts from the housefly, Musca domestica, reduce ecdysteroid synthesis and inhibit egg development when injected into the mosquito, Aedes atropalpus (Kelley et al., 1984). In the blow fly, Calliphora vicina, ecdysteroid synthesis in the larval ring gland appears to be regulated by a very potent inhibitory factor derived from the abdominal ganglion and subesophageal ganglion (Budd et al., 1993). A trypsin modulating oostatic factor (TMOF) isolated from the ovaries of adult females of flesh fly, Neobellieria bullata, is the first identified factor with prothoracicostatic activity (Hua et al., 1994). N. bullata TMOF inhibits ecdysteroid biosynthesis in the larval ring gland of flies (Hua and Koolman, 1995), 
Table 1 | List of peptides and biogenic amine taken up in this review.

\begin{tabular}{|c|c|c|c|}
\hline Name & Structure & Tropic/static & References \\
\hline \multicolumn{4}{|l|}{ B. MORI } \\
\hline PROTHORACICOTROPIC & GNIQVENQAIPDPPCTCKYKKEIEDLGENSVPRFIET & Tropic & Kawakami et al. (1990) \\
\hline \multirow[t]{2}{*}{ HORMONE (PTTH) } & RNCNKTQQPTCRPPYICKESLYSITILKRRETKSQESL & & \\
\hline & EIPNELKYRWVAESHPVSVACCLCTRDYQLRYNNN & & \\
\hline \multicolumn{4}{|c|}{ PROTHORACICOSTATIC PEPTIDES (PTSPs) } \\
\hline PTSP-I & AWODLNSAWa & Static & Hua et al. (1999), Yamanaka et al. (2010) \\
\hline PTSP-II & GWODLNSAWa & & \\
\hline PTSP-III & APEKWAAFHGSWa & & \\
\hline PTSP-IV & GWNDISSWWa & & \\
\hline PTSP-V & AWODMSSAWa & & \\
\hline PTSP-VI & AWSALHGTWa & & \\
\hline PTSP-VII & AWODLNSWWa & & \\
\hline PTSP-VIII & AWSSLHSGWA & & \\
\hline BOMMO-MYOSUPPRESSIN (BMS) & pEDWHSFLRFa & Static & Yamanaka et al. (2005) \\
\hline \multicolumn{4}{|c|}{ BOMMO-FMRF-AMIDE-RELATED PEPTIDE (BRFa) } \\
\hline BRFa-I & SAIDRSMIRFa & Static & Yamanaka et al. (2006) \\
\hline BRFa-II & SASFVRFa & & \\
\hline BRFa-III & DPSFIRFa & & \\
\hline BRFa-IV & ARNHFIRLa & & \\
\hline \multicolumn{4}{|l|}{ ORCOKININ } \\
\hline Bommo-orc-I & NFDEIDESSLNTFV & Tropic & Roller et al. (2008), Yamanaka et al. (2011) \\
\hline Bommo-orc-II & NFDEIDRSSMPFPYAI & & \\
\hline \multicolumn{4}{|l|}{ FXPRL-AMIDE } \\
\hline Diapause hormone (DH) & TDMKDESDRGAHSERGALWFGPRLa & Tropic & Watanabe et al. (2007) \\
\hline \multicolumn{4}{|l|}{ BIOGENIC AMINE } \\
\hline Octopamine & $\mathrm{OH}$ & Tropic & Hirashima et al. (1999) \\
\hline \multicolumn{4}{|l|}{ OTHER INSECTS } \\
\hline N. bullataTMOF & NPTNLH & Static & Hua et al. (1994), Hua and Koolman (1995) \\
\hline G. bimaculatus AST-B1 & GWODLNGGWa & Static & Lorenz et al. (1998) \\
\hline H. arm/gera DH-like peptide & NDVKDGAASGAHSDRLGLWFGPRLa & Tropic & Zhang et al. (2004) \\
\hline N. bullata pyrokinin-II & SVOFKPRLa & Tropic & Verleyen et al. (2004) \\
\hline
\end{tabular}

but $N$. bullata TMOF is not present in the central nervous system of the larvae (Bylemans et al., 1996). Allatostatin-B (AST-B) isolated from adult brains of the cricket, Gryllus bimaculatus, has been observed to decrease the hemolymph ecdysteroid titer in the adult of G. bimaculatus (Lorenz et al., 1998) but the PGs do not produce physiologically significant amounts of ecdysteroids at this stage (Hoffmann et al., 1998). Thus, no endogenous prothoracicostatic factor had been identified until the isolation of prothoracicostatic peptide (PTSP) from larval brains of $B$. mori (Hua et al., 1999).

Prothoracicostatic peptide has the same sequence as Mansemyoinhibitory peptide-I (MIP-I), which was previously isolated from the nerve cord of the adult $M$. sexta (Blackburn et al., 1995). PTSP also shows high sequence homology to G. bimaculatus AST-B. This peptide inhibits both basal and PTTH-stimulated ecdysteroidogenesis in vitro in a dose-dependent manner, and injection of synthetic PTSP has been shown to temporally decrease the hemolymph ecdysteroid titer in fifth instar larvae of $B$. mori
(Liu et al., 2004). Interestingly, the peripheral neuroendocrine system - the epiproctodeal gland - is the principal site of neurohemal release of MIP in M. sexta (Davis et al., 2003): MIPimmunostaining in the epiproctodeal gland begins to increase during the first half of the molting period, and then most of the immunostaining is rapidly lost within several hours. This rapid loss of immunostaining suggests that a massive release of MIP from the epiproctodeal gland into hemolymph occurs at this stage, when there is a rapid decline in the ecdysteroid titer. The release of PTSP from the epiproctodeal gland also appears to occur at the same stage in $B$. mori, while the expression of $p t s p$ in the brain is high during the feeding stage and low during the molting stage (Yamanaka et al., 2010).

Recently, a B. mori G protein-coupled receptor, which had previously been identified as an ortholog of the Drosophila sex peptide receptor (Yapici et al., 2008), is characterized as a functional PTSP receptor (Yamanaka et al., 2010). This receptor responds specifically to PTSP when examined using a heterologous expression 
system. The receptor is expressed at low levels during the feeding stage, but is highly expresses in the PGs on the day before each larval and pupal ecdysis, when massive release of PTSP from the epiproctodeal gland occurs. These results suggest that PTSP secreted from the epiproctodeal gland acts on the PGs through the PTSP receptor during the molting cycle in $B$. mori and that the peripheral neurosecretory cells, as well as the neurosecretory system in the central nervous system, play a stage-specific role in regulating ecdysteroidogenesis. PTSP is unlikely to be involved in initiating the decrease in the ecdysteroid titer, but is probably involved in either full inactivation or suppression of re-activation of the PGs to finely regulate the ecdysteroid titer in the hemolymph (Yamanaka et al., 2010).

Another prothoracicostatic factor purified from pupal brains of $B$. mori is a decapeptide that shows the conserved structure of an insect myosuppressin, and has thus been named Bommo-myosuppressin (BMS; Yamanaka et al., 2005). Myosuppressin is a member of a larger peptide family of FMRF-amiderelated peptides (FaRPs), which are known to regulate a wide range of processes from behavior to physiology in invertebrates (Mackey et al., 1987; Nelson et al., 1998; Nicols, 2003). BMS dose-dependently suppresses the cAMP level and inhibits ecdysteroidogenesis in the larval PGs at much lower concentrations than PTSP. The specific receptor for BMS is highly expressed in the PGs at the feeding stage. Together, these results suggest that BMS is secreted from the brain and plays an important role in maintaining low ecdysteroid levels during the feeding stage in the hemolymph. Vertebrates including humans have also been shown to possess peptides with RF-amide at the C-terminus (Yang et al., 1985), and at least one RF-amide peptide has been shown to inhibit steroid hormone release in experiments using an in vitro adrenal slice culture system (Labrouche et al., 1998). RF-amide peptides may modulate steroid hormone secretion throughout metazoans, thereby controlling post-embryonic development.

FXPRL-amide peptides, which are not homologous with PTTH, can stimulate ecdysteroidogenesis by the PGs. Diapause hormone (DH) which was identified as an inducer of embryonic diapause in B. mori (Imai et al., 1991), stimulates ecdysteroidogenesis by the PGs of late fifth instar larvae of B. mori (Watanabe et al., 2007). The receptor for DH is expressed in the PGs, as well as in pupal pheromone glands and ovaries prior to eclosion, and the expression of this receptor in the PGs increases from the last half of the fifth instar stage to the first day of the pupal stage. These results suggest that $\mathrm{DH}$ regulates ecdysteroidogenesis during the late stages of fifth instar larvae in B. mori. Possible prothoracicotropic effects of FXPRL-amide peptides have been reported in other insects. In the cotton bollworm Helicoverpa armigera, $\mathrm{DH}$-like peptide can break the pupal diapause by activating the ecdysteroidogenesis by PGs in a temperature-dependent manner (Zhang et al., 2004). The pupariation of N. bullata, is accelerated by a FXPRL-amide peptide, $N$. bullata pyrokinin-II (Verleyen et al., 2004). Taken together, these results suggest that FXPRLamide peptides can function as prothoracicotropic factors across insect species and may play important roles in post-embryonic insect development.

\section{NEURAL REGULATION}

Since the first report of neural innervation in the PGs by Lyonet (1762; Figure 1A), the importance of PG-innervating neurons in the control of ecdysteroidogenesis has been well documented (Scharrer, 1964; Srivastava and Singh, 1968; HintzePodufal, 1970; Giebultowicz and Denlinger, 1985). In B. mori, the PGs are innervated by seven nerves starting from the subesophageal ganglion, prothoracic ganglia and mesothoracic ganglia, and by unpaired nerves between the above-mentioned ganglia (Figure 1B, Yokoyama, 1956). A positive correlation between the levels of electrical activity of PG-innervating neurons and the ecdysteroid titer during the course of development in the last larval instar has been reported in the American cockroach Periplaneta americana (Richter and Gersch, 1983), while the electrical activity shows an inverse relationship with ecdysteroid titer in the cabbage moth Mamestra brassicae (Okajima and Watanabe, 1989).

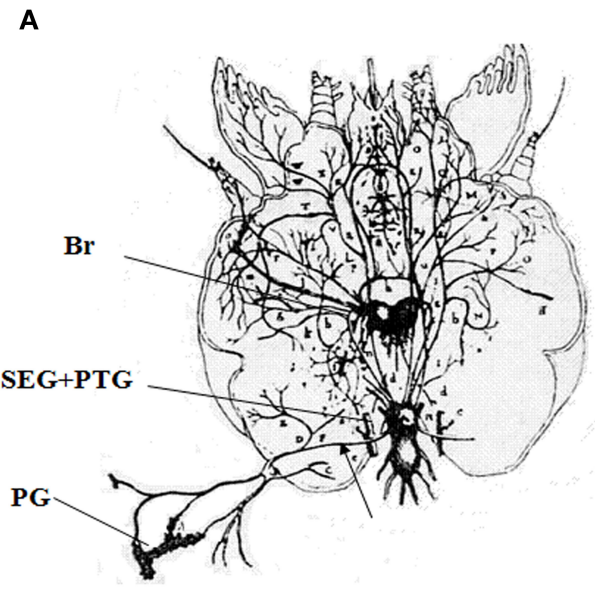

FIGURE 1 | Historical descriptions of neurons innervating the prothoracic gland. (A) The first description of innervating neurons of the moth by Lyonet (1762). (B) Innervating neurons in the larva of Bombyx mori reported by Yokoyama (1956). Br, brain; SEG, subesophageal ganglia; PTG, prothoracic

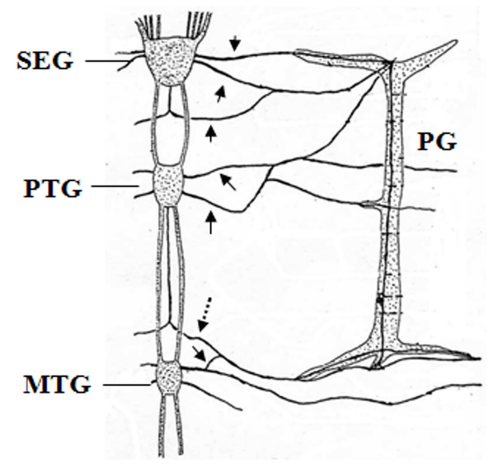

ganglia; MTG, mesothoracic ganglia; PG, prothoracic gland. Arrows indicate the neurons innvervating the PGs, and a dotted arrow indicates the BRFa/Orcokinin-neuron. These figures are partially modified from the original ones. 
However, studies revealing the molecular basis of regulation by the PGs have been restricted to hormonal factors throughout the last century.

Recently, for the first time we revealed the molecular basis of neural regulation of ecdysteroidogenesis in B. mori (Yamanaka et al., 2006). We found that Bommo-FMRF related peptide (BRFa) regulates ecdysteroidogenesis through direct innervation of the PGs in B. mori. BRFa is predominantly expressed in the prothoracic ganglion, and neurons in the prothoracic ganglion innervate the PGs and supply BRFa to the surface of PGs (Figure 1B). Electrophysiological recordings during development confirmed the increased firing activity of BRFa-expressing neurons in developmental stages of low PG activity and decreased ecdysteroid levels in the hemolymph. The prothoracicostatic function of BRFa has been confirmed by the report that BRFa neurons suppress the expression of several P450 genes induced by PTTH in the PGs (Yamanaka et al., 2007).

We found that other neuropeptides are delivered to the surface of the PGs through PG-innervating neurons (Yamanaka et al., 2011). Using direct mass spectrometric profiling of axons associated with the PGs, we detected several peptide peaks corresponding to orcokinin gene products in addition to BRFa. One of the two pairs of BRFa-expressing neurosecretory cells in the prothoracic ganglion co-expresses orcokinin, and these neurons project axons through the transverse nerve and terminate on the surface of the PGs (Figure 1B). Orcokinin was originally isolated from the nervous system of the spinycheek crayfish Orconectes limosus as a myostimulatory factor (Stangier et al., 1992). Orcokinin-like peptides have subsequently been identified in several insects (Pascual et al., 2004; Hofer et al., 2005; Liu et al., 2006; Christie, 2008; Roller et al., 2008; Clynen and Schoofs, 2009), although their physiological functions remain largely unknown except for a few cases (Hofer and Homberg, 2006). In. B. mori, orcokinins have clear prothoracicotropic activity and are able to cancel the static effect of BRFa on ecdysteroid biosynthesis, whereas the suppressive effect of BRFa on CAMP production remains unchanged in the presence of orcokinins (Yamanaka et al., 2011). The acute effects of prothoracicotropic or prothoracicostatic factors which becomes manifest temporally during short-term in vitro incubation of the PG are mediated by translation and phosphorylation of intercellular molecules involved in the signal transduction of ecdysteroidogenesis (Gilbert et al., 2002; Huang et al., 2008; Rewitz et al., 2009a). On the other hand, the chronic effects of these factors which become obvious on a longer time scale during development are mediated by the transcriptional regulation of some genes encoding ecdysteroidogenic enzymes probably via cAMP-mediated pathway (Gilbert et al., 2002; Huang et al., 2008). The chronic effects of these factors are pharmacologically separable from the acute effects (Yamanaka et al., 2007). Thus, orcokinins might regulate ecdysteroidogenesis by the PGs via cAMP-independent way; that is, they specifically eliminate the acute prothoracicostatic effect of $\mathrm{BRFa}$ while maintaining the chronic inhibitory effect of BRFa. The signaling pathway of orcokinin at the molecular level needs to be elucidated to prove this hypothesis.

What is the functional significance of such a complex feature of the PG-innervating neurons in $\mathrm{B}$. mori? It is known that a low level of ecdysteroid titer during the intermolt period has a complex

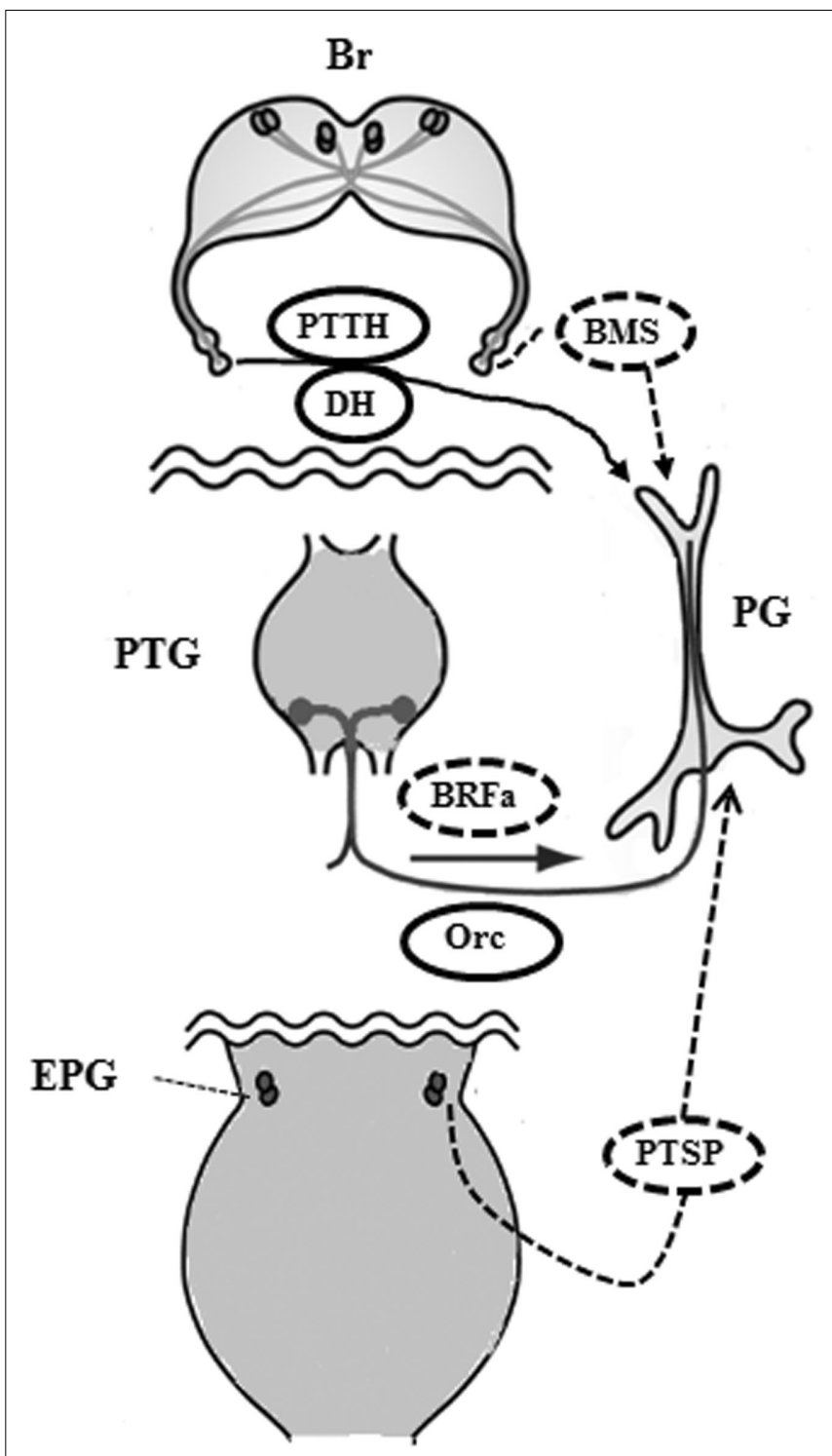

FIGURE 2 | Proposed regulatory mechanism of ecdysteroidogenesis by the prothoracic gland in the larva of Bombyx mori. During the feeding stage, BRFa and orcokinin are delivered through the innervating neurons to maintain low levels of ecdysteroid in collaboration with circulating BMS Next, PTTH and DH are released to stimulate ecdysteroidogenesis after the release of inhibition by BRFa and BMS. PTSP is secreted from the epiproctodeal gland after the ecdysteroid level reaches a peak in order to decrease ecdysteroid levels rapidly. Br, brain; PTG, prothoracic ganglia; PG, prothoracic gland; EPG, epiproctodeal gland; Orc, orcokinin. Solid ovals indicate tropic factors and dotted ovals indicate static factors.

effect on the regulation of tissue growth and proliferation (Champlin and Truman, 1998; Colombani et al., 2005; Nijhout et al., 2007). Therefore, orcokinins might maintain a low ecdysteroid titer while BRFa suppresses full potentiation of the PGs prior to the ecdysteroid pulse generated by PTTH (Mizoguchi et al., 2001).

Prothoracic gland-innervating neurons of other lepidopteran insects are also stained by both FMRFa- and orcokinin-specific antibodies (Tanaka, unpublished data). In D. melanogaster, a pair 
of bilaterally symmetric neurons located in the cerebral labrum portion of the brain directly innervate the PGs (Siegmund and Korge, 2001) and induce the production and secretion of ecdysone by delivering PTTH directly (McBrayer et al., 2007); however, it is not certain whether other peptides are delivered to the PGs through these innervating neurons. By contrast, PG-innervating neurons are not stained by PTTH-specific antibody in B. mori (Tanaka, unpublished data). Different peptidergic systems may regulate ecdysteroidogenesis among the various insect species.

\section{FUTURE PROSPECTS}

Bombyx mori has been a useful tool for insect endocrinology since the discovery of PG function by Fukuda (1944), and studies have shown that ecdysteroidogenesis by the PGs is under the control of a complex mechanism (Figure 2). Tropic and static factors, the peripheral neurosecretory system as well as the central neuroendocrine system, and neural regulation in addition to circulating factors all collaborate to regulate ecdysteroidogenesis by the PGs. Thus, together they create the finely tuned fluctuations in ecdysteroid titer needed in the hemolymph during the development of B. mori. Moreover, we should carefully re-investigate factors and mechanisms that have been ignored for a long time. For example, the roles of biogenic amines in ecdysteroidgenesis remain unclear, although it has been reported that octopamine stimulates the production of ecdysteroids by larval PGs of B. mori in vitro (Hirashima et al., 1999). How the PGs relay their con-

\section{REFERENCES}

Blackburn, M. B., Wagner, R. M., Kochansky, J. P., Harrison, D. J., Thomas-Laemont, P., and Raina, A. K. (1995). The identification of two myoinhibitory peptides, with sequence similarities to the galanins, isolated from the ventral nerve cord of Manduca sexta. Regul. Pept. 57, 213-219.

Budd, E., Kauser, G., and Koolman, J. (1993). On the control of ecdysone biosynthesis by the central nervous system of blowfly larvae. Arch. Insect Biochem. Physiol. 23, 181-197.

Bylemans, D., Verhaert, P., Janssen, I., Vanden Broeck, J., Borovsky, D., Ma, M., and De Loof, A. (1996). Immunolocalization of the oostatic and prothoracicostatic peptide, Neb-TMOF, in adults of the fleshfly, Neobellieria bullata. Gen. Comp. Endocrinol. 103, 273-280.

Carlisle, D. B., and Ellis, P. E. (1968). Hormonal inhibition of the prothoracic gland by the brain in locusts. Nature 220, 706-707.

Champlin, D. T., and Truman, J. W. (1998). Ecdysteroids govern two phases of eye development during metamorphosis of the moth, Manduca sexta. Development 125, 2009-2018.

Christie, A. E. (2008). In silico analyses of peptide paracrines/hormones in
Aphidoidea. Gen. Comp. Endocrinol. 159, 67-79.

Clynen, E., and Schoofs, L. (2009). Peptidomic survey of the locust neuroendocrine system. Insect Biochem. Mol. Biol. 39, 491-507.

Colombani, J., Bianchini, L., Layalle, S., Pondeville, E., Dauphin-Villemant, C., Antoniewski, C., Carre, C., Noselli, S., and Leopold, P. (2005). Antagonistic actions of ecdysone and insulins determine final size in Drosophila. Science 310, 667-670.

Davis, N. T., Blackburn, M. B., Golubeva, E. G., and Hildebrand, J. G. (2003). Localization of myoinhibitory peptide immunoreactivity in Manduca sexta and Bombyx mori, with indications that the peptide has a role in molting and ecdysis. J. Exp. Biol. 206, 1449-1460.

Fukuda, S. (1944). The hormonal mechanism of larval molting and metamorphosis in the silkworm. J. Fac. Sci. Tokyo Imperial Univ. Sec. IV 6, 477-532.

Gibbens, Y. Y., Warren, J. T., Gilbert, L. I., and O'Connor, M. B. (2011). Neuroendocrine regulation of Drosophila metamorphosis requires TGFbeta/Activin signaling. Development 138, 2693-2703.

Giebultowicz, J. M., and Denlinger, D. L. (1985). Identification of neurons innervating the ring gland

dition to the neural system is not yet fully understood, but the PG-innervating neurons may be involved in this communication. Three PG-innervating neurons contain afferent neurons as well as efferent ones in M. brassicae (Okajima and Watanabe, 1989). Although the function of these afferent neurons is unknown, the CNS may be monitoring the condition of the PGs via these neurons.

The neuropeptides responsible for the ecdysteroidogenesis in $B$. mori are commonly present among insect species, but their function in ecdysteroidogenesis remains to be elucidated in other insects. No prothoracicostatic factor has been identified as yet in $D$. melanogaster, and the importance of insulin signaling in regulating ecdysteroid production by the PGs has been recently highlighted (see the review by Marchal et al., 2010 and the recent topics by Gibbens et al., 2011). The regulatory mechanisms of ecdysteroidogenesis by the PGs may be diverse among insect species and need to be elucidated in different insect models in order to understand how the insects adapted to diverse environment.

\section{ACKNOWLEDGMENTS}

I specially thanks Drs. Naoki Yamanaka, Yue-Jin Hua, Ladislav Roller, Dusan Žitnan, Akira Mizoguchi, and Hiroshi Kataoka for the studies on PTSP, BMS, BRFa, and orcokinin. These studies were supported by the Grants-in-Aid for Scientific Research from the Japan Society for the Promotion of Science (JSPS, Grant 21380040).

of the flesh fly larva. Sarcophaga crassipalpis Macquart (Diptera: Sarcophagidae). Int. J. Insect Morphol. Embryol. 14, 155-161.

Gilbert, L. I., Rybczynski, R., and Warren, J. T. (2002). Control and biochemical nature of the ecdysteroidogenic pathway. Annu. Rev. Entomol. 47, 883-916.

Hintze-Podufal, C. (1970). Innervation of prothoracic glands of Cerura vinula L. (Lepidoptera). Experientia 26, 1269-1271.

Hirashima, A., Hirokado, S., Ohta, H., Suetsugu, E., Sakaguchi, M., Kuwano, E., Taniguchi, E., and Eto, M. (1999). Titres of biogenic amines and ecdysteroids: effect of octopamine on the production of ecdysteroids in the silkworm Bombyx mori. J. Insect Physiol. 45, 843-851.

Hofer, S., Dircksen, H., Tollback, P., and Homberg, U. (2005). Novel insect orcokinins: characterization and neuronal distribution in the brains of selected dicondylian insects. J. Comp. Neurol. 490, 57-71.

Hofer, S., and Homberg, U. (2006). Evidence for a role of orcokinin-related peptides in the circadian clock controlling locomotor activity of the cockroach Leucophaea maderae. J. Exp. Biol. 209, 2794-2803.
Hoffmann, K. H., Lorenz, M. W., and Oeh, U. (1998). Ecdysteroid release by the prothoracic gland of Gryllus bimaculatus (Ensifera: Gryllidae) during larval-adult development. J. Insect Physiol. 44, 941-946.

Hua, Y. J., Bylemans, D., De Loof, A., and Koolman, J. (1994). Inhibition of ecdysone biosynthesis in flies by a hexapeptide isolated from vitellogenic ovaries. Mol. Cell. Endocrinol. 104, R1-R4.

Hua, Y.-J., and Koolman, J. (1995). An ecdysiostatin from flies. Regul. Pept. 57, 263-271.

Hua, Y. J., Tanaka, Y., Nakamura, K., Sakakibara, M., Nagata, S., and Kataoka, H. (1999). Identification of a prothoracicostatic peptide in the larval brain of the silkworm, Bombyx mori. J. Biol. Chem. 274, 31169-31173.

Huang, X., Warren, J. T., and Gilbert, L. I. (2008). New players in the regulation of ecdysone biosynthesis. $J$. Genet. Genomics 35, 1-10.

Imai, K., Konno, T., Nakazawa, Y., Komiya, T., Isobe, M., Koga, K., Goto, T., Yaginuma, T., Sakakibara, K., Hasegawa, K., and Yamashita, O. (1991). Isolation and structure of diapause hormone of the silkworm, Bombyx mori. Proc. Jpn. Acad. 67B, 98-101. 
Kawakami, A., Kataoka, H., Oka, T., Mizoguchi, A., Kimura-Kawakami, M., Adachi, T., Iwami, M., Nagasawa, H., Suzuki, A., and Ishizaki, H. (1990). Molecular cloning of Bombyx mori prothoracocotropic hormone. Science 247, 1333-1335.

Kelley, T. J., Birnbaum, M. J., Woods, C. W., and Borkovec, A. B. (1984). Effects of house fly oostatic hormone on egg development neurosecretory homone action in Aedes atropalpus. J. Exp. Zool. 229, 491-496.

Kobayashi, M. (1957). Studies on the neurosecretion in the silkworm, Bombyx mori L. Bull. Sericult. Exp. Sta. 15, 181-273.

Kopeć, S. (1922). Studies on the necessity of the brain for the inception of insect metamorphosis. Biol. Bull. 42, 323-342.

Labrouche, S., Laulin, J. P., Le Moal, M., Tramu, G., and Simonnet, G. (1998). Neuropeptide FF in the rat adrenal gland: presence, distribution and pharmacological effects. $J$. Neuroendocrinol. 10, 559-565.

Liu, F., Baggerman, G., D’Hertog, W., Verleyen, P., Schoofs, L., and Wets, G. (2006). In silico identification of new secretory peptide genes in Drosophila melanogaster. Mol. Cell. Proteomics 5, 510-522.

Liu, X., Tanaka, Y., Song, Q., Xu, B., and Hua, Y. (2004). Bombyx mori prothoracicostatic peptide inhibits ecdysteroidogenesis in vivo. Arch. Insect Biochem. Physiol. $56,155-161$.

Lorenz, M. W., Lorenz, J. I., Treiblmayr, K., and Hoffmann, K. H. (1998). In vivo effects of allatostatins in crickets, Gryllus bimaculatus (Ensifera: Gryllidae). Arch. Insect Biochem. Physiol. 38, 32-43.

Lyonet, P. (1762). Traité anatomique de la chenille aui ronge le bois de Saule. Amsterdam: La Haye, P616.

Mackey, S. L., Glanzman, D. L., Small, S. A., Dyke, A. M., Kandel, E. R., and Hawkins, R. D. (1987). Tail shock produces inhibition as well as sensitization of the siphon-withdrawal reflex of Aplysia: possible behavioral role for presynaptic inhibition mediated by the peptide Phe-MetArg-Phe-NH2. Proc. Natl. Acad. Sci. U.S.A. 84, 8730-8734

Marchal, E., Vandersmissen, H. P., Badisco, L., Van de Velde, S., Verlinden, H., Iga, M., Van Wielendaele, P., Huybrechts, R., Simonet, G., Smagghe, G., and Vanden Broeck, J. (2010). Control of ecdysteroidogenesis in prothoracic glands of insects: a review. Peptides 31, 506-519.

McBrayer, Z., Ono, H., Shimell, M., Parvy, J. P., Beckstead, R. B., Warren,
J. T., Thummel, C. S., DauphinVillemant, C., Gilbert, L. I., and O'Connor, M. B. (2007). Prothoracicotropic hormone regulates developmental timing and body size in Drosophila. Dev. Cell 13, 857-871.

Mizoguchi, A., Ohashi, Y., Hosoda, K., Ishibashi, J., and Kataoka, H. (2001). Developmental profile of the changes in the prothoracicotropic hormone titer in hemolymph of the silkworm Bombyx mori: correlation with ecdysteroid secretion. Insect Biochem. Mol. Biol. 31, 349-358.

Mizoguchi, A., Oka, T., Kataoka, H., Nagasawa, H., Suzuki, A., and Ishizaki, H. (1990). Immunohistochemical localization of prothoracicotropic hormone-producing neurosecretory cells in the brain of Bombyx mori. Dev. Growth Differ. 32, 591-598.

Nelson, L. S., Rosoff, M. L., and Li, C. (1998). Disruption of a neuropeptide gene, flp-1, causes multiple behavioral defects in Caenorhabditis elegans. Science 281, 1686-1690.

Nicols, R. (2003). Signaling pathways and physiological functions of Drosophila melanogaster FMRFamide-related peptides. Annu. Rev. Entomol. 48, 485-503.

Nijhout, H. F., Smith, W. A., Schachar, I., Subramanian, S., Tobler, A., and Grunert, L. W. (2007). The control of growth and differentiation of the wing imaginal disks of Manduca sexta. Dev. Biol. 302, 569-576.

Okajima, A., and Watanabe, M. (1989). Electrophysiological identification of neural pathway to the prothoracic gland and the change in electrical activities of the prothoracic gland innervating neurons during larval development of a moth, Mamestra brassicae. Zool. Sci. 6, 459-468.

Pascual, N., Castresana, J., Valero, M. L., Andreu, D., and Belles, X. (2004). Orcokinins in insects and other invertebrates. Insect Biochem. Mol. Biol. 34, 1141-1146.

Rewitz, K. F., Larsen, M. R., LobnerOlesen, A., Rybczynski, R., O'Connor, M. B., and Gilbert, L. I. (2009a). A phosphoproteomics approach to elucidate neuropeptide signal transduction controlling insect metamorphosis. Insect Biochem. Mol. Biol. 39, 475-483.

Rewitz, K. F., Yamanaka, N., Gilbert, L. I., and O'Connor, M. B. (2009b). The insect neuropeptide PTTH activates receptor tyrosine kinase torso to initiate metamorphosis. Science 326, 1403-1405.

Richter, K., and Gersch, M. (1983). Electrophysiological evidence of nervous involvement in the control of the prothoracic gland in Periplaneta americana. Experientia 39, 917-918.

Roller, L., Yamanaka, N., Watanabe, K., Daubnerova, I., ZZitnan, D., Kataoka, H., and Tanaka, Y. (2008). The unique evolution of neuropeptide genes in the silkworm Bombyx mori. Insect Biochem. Mol. Biol. 38, 1147-1157.

Scharrer, B. (1964). The fine structure of Blattarian prothoracic glands. Z. Zellforsch. Mikrosk. Anat. 64, 111-119.

Siegmund, T., and Korge, G. (2001). Innervation of the ring gland of Drosophila melanogaster. J. Comp. Neurol. 431, 481-491.

Srivastava, K. P., and Singh, H. H. (1968). On innervation of prothoracic glands in Papilio demoleus L. (Lepidoptera). Experientia 24, 838-839.

Stangier, J., Hilbich, C., Burdzik, S., and Keller, R. (1992). Orcokinin: a novel myotropic peptide from the nervous system of the crayfish, Orconectes limosus. Peptides 13, 859-864.

Truman, J. W. (1972). Physiology of insect rhythms I. Circadian organization of the endocrine events underlying the molting cycle of larval tobacco hornworms. J. Exp. Biol. $57,805-820$.

Verleyen, P., Clynen, E., Huybrechts, J., Van Lommel, A., Vanden Bosch, L. De Loof, A., Zdarek, J., and Schoofs, L. (2004). Fraenkel's pupariation factor identified at last. Dev. Biol. 273, 38-47.

Watanabe, K., Hull, J. J., Niimi, T., Imai, K., Matsumoto, S., Yaginuma, T., and Kataoka, H. (2007). FXPRLamide peptides induce ecdysteroidogenesis through a G-protein coupled receptor expressed in the prothoracic gland of Bombyx mori. Mol. Cell. Endocrinol. 273, 51-58.

Yamanaka, N., Honda, N., Osato, N., Niwa, R., Mizoguchi, A., and Kataoka, H. (2007). Differential regulation of ecdysteroidogenic P450 gene expression in the silkworm, Bombyx mori. Biosci. Biotechnol. Biochem. 71, 2808-2814.

Yamanaka, N., Hua, Y. J., Mizoguchi, A., Watanabe, K., Niwa, R., Tanaka, Y., and Kataoka, H. (2005). Identification of a novel prothoracicostatic hormone and its receptor in the silkworm Bombyx mori. J. Biol. Chem. 280, 14684-14690.

Yamanaka, N., Hua, Y. J., Roller, L., Spalovska-Valachova, I., Mizoguchi, A., Kataoka, H., and Tanaka, Y. (2010). Bombyx prothoracicostatic peptides activate the sex peptide receptor to regulate ecdysteroid biosynthesis. Proc. Natl. Acad. Sci. U.S.A. 107, 2060-2065.
Yamanaka, N., Roller, L., Ẑitnan, D., Satake, H., Mizoguchi, A., Kataoka, H., and Tanaka, Y. (2011). Bombyx orcokinins are brain-gut peptides involved in the neuronal regulation of ecdysteroidogenesis. J. Comp. Neurol. 519, 238-246.

Yamanaka, N., Ẑitnan, D., Kim, Y. J., Adams, M. E., Hua, Y. J., Suzuki, Y., Suzuki, M., Suzuki, A., Satake, H., Mizoguchi, A., Asaoka, K., Tanaka,Y., and Kataoka, H. (2006). Regulation of insect steroid hormone biosynthesis by innervating peptidergic neurons. Proc. Natl. Acad. Sci. U.S.A. 103, 8622-8627

Yang, H. Y., Fratta, W., Majane, E. A., and Costa, E. (1985). Isolation, sequencing, synthesis, and pharmacological characterization of two brain neuropeptides that modulate the action of morphine. Proc. Natl. Acad. Sci. U.S.A. 82, 7757-7761.

Yapici, N., Kim, Y. J., Ribeiro, C., and Dickson, B. J. (2008). A receptor that mediates the post-mating switch in Drosophila reproductive behaviour. Nature 451, 33-37.

Yokoyama, T. (1956). The morphology and innervation of the prothoracic gland in the silkworm, Bombyx mori. J. Sericult. Sci. Jpn. 25, 87-94.

Zhang, T. Y., Sun, J. S., Zhang, Q. R., $\mathrm{Xu}, \mathrm{J}$., Jiang, R. J., and $\mathrm{Xu}, \mathrm{W}$. H. (2004). The diapause hormonepheromone biosynthesis activating neuropeptide gene of Helicoverpa armigera encodes multiple peptides that break, rather than induce, diapause. J. Insect Physiol. 50, 547-554.

Conflict of Interest Statement: The author declares that the research was conducted in the absence of any commercial or financial relationships that could be construed as a potential conflict of interest.

Received: 28 October 2011; paper pending published: 10 November 2011; accepted: 06 December 2011; published online: 29 December 2011.

Citation: Tanaka Y (2011) Recent topics on the regulatory mechanism of ecdysteroidogenesis by the prothoracic glands in insects. Front. Endocrin. 2:107. doi: 10.3389/fendo.2011.00107

This article was submitted to Frontiers in Experimental Endocrinology, a specialty of Frontiers in Endocrinology.

Copyright () 2011 Tanaka. This is an open-access article distributed under the terms of the Creative Commons Attribution Non Commercial License, which permits non-commercial use, distribution, and reproduction in other forums, provided the original authors and source are credited. 